\title{
A REVIEW OF PALATAL CANCERS SECONDARY TO REVERSE SMOKING HABIT IN EAST GODAVARI DISTRICT OF ANDHRA PRADESH
}

\author{
Srikanth Ranganatha Rao', Srinivas Manne ${ }^{2}$, Prashant Pidaparthy ${ }^{3}$ \\ ${ }^{1}$ Associate Professor, Department of Radiotherapy, Government General Hospital. \\ ${ }^{2}$ Assistant Professor, Department of Radiotherapy, Government General Hospital. \\ 3Tutor, Department of Radiotherapy, Government General Hospital.
}

\section{ABSTRACT}

\section{BACKGROUND}

To study the occurrence of Palatal cancers secondary to "reverse smoking habit," its incidence and its response to treatment in the East Godavari district of Andhra Pradesh.

\section{MATERIALS AND METHODS}

Patients coming to Cancer Wing of Government General Hospital, Kakinada, Andhra Pradesh with histopathological or cytological evidence of Palatal cancer, consequent to the habit of reverse smoking were analysed retrospectively. Patients were treated with chemo-irradiation either alone or after Neoadjuvant chemotherapy.

\section{RESULTS}

The study revealed a definite correlation between the habit of reverse smoking habit in this region and higher incidence of palatal cancers, particularly squamous cell carcinomas. However, the response to chemo-irradiation of this group of cancers as compared to the results reported in the literature is better. The response rates reported in stage III/IV palatal cancers are 48\% (Yor ozu A, Sykes AJ, et al) at 3 years, while our study shows responses of $80 \%$ at first follow-up and remained at $60 \%$.

\section{CONCLUSIONS}

The peculiar habit of reverse smoking exists in low socioeconomic and tribal population of East Godavari district. There is definite increase in incidence of palatal cancers due to this habit. Palatal cancers due to the habit of Reverse smoking can be considered as preventable cancers, in that counselling for giving up the habit can drastically reduce its incidence in this part of the country. Early diagnosis and treatment can secondarily control the cancer in view of its better responses. Rehabilitation after treatment by of dental counselling can reduce the complications.

\section{KEYWORDS}

Reverse Smoking, Palatal Cancer, East Godavari District.

HOW TO CITE THIS ARTICLE: Rao SR, Manne S, Pidaparthy P. A review of palatal cancers secondary to reverse smoking habit in East Godavari district of Andhra Pradesh. J. Evolution Med. Dent. Sci. 2016;5(75):5542-5545, DOI: 10.14260/jemds/2016/1252

\section{INTRODUCTION}

Palatal cancers are relatively uncommon of the head and neck malignancies world over. They constitute only $2 \%$ of head and neck malignancies and 6 to $9 \%$ of oral cancers (Ref - Cancer Research, UK 2013). Predominant malignancies in this region include cancers of the tongue, buccal mucosa, alveoli; Tonsils etc. (Shodganga et al) Tobacco and Alcohol are known to be the foremost of the aetiologies of malignancies occurring in this region. $(1,2,3)$

Head and neck malignancies rank amongst top five cancers afflicting the population of East Godavari district. It is the commonest of the cancers in males and in females it comes third after Breast and Cervix cancers in incidence. Amongst the Head and Neck cancers, though tongue and buccal malignancies predominate the incidence of palatal cancers is noticeably high in the East Godavari district, especially in the

Financial or Other, Competing Interest: None.

Submission 29-07-2016, Peer Review 02-09-2016,

Acceptance 09-09-2016, Published 17-09-2016.

Corresponding Author:

Dr. Srikanth Ranganatha Rao,

Flat No. 101, 2-2-1144/25/7,

Sapthagiri Residency,

New Nallakunta,

Hyderabad-500044.

E-mail: srikanthsapthagiri@yahoo.com

DOI: $10.14260 /$ jemds $/ 2016 / 1252$

\section{(c) $(1)$}

low socioeconomic class and the tribal population and constitutes nearly $20 \%$ of them. 4,5 This is attributable to the habit of "Reverse smoking," locally termed as "Adda Poga" or "Adda Chutta" which simply means putting the burning end of the cigar inside the mouth and inhaling the smoke. $(5,6)$

An attempt is made in this study to establish the causality of "reverse smoking" in the incidence of palatal cancers and to observe the behaviour and response to treatment of group of malignancies compared to cancers due to other causes.

From this study, it has been observed that there is apparently higher incidence of palatal cancers in those persons with the habit of reverse smoking. ${ }^{(7,8)}$ It is also apparent from the study that results of chemo-irradiation in this group of cancers are marginally better compared to the cancers of palate from other causes. 9,10

\section{SUBJECTS AND METHODS}

Patients coming to the Cancer Wing of Government General Hospital, Kakinada, East Godavari district were considered retrospectively. Amongst them cases of palatal cancers, both hard and soft palatal cancers, which were histopathologically or cytologically proven were selected. Only those cases with history of addiction to reverse smoking were chosen for the study.

Overall 62 cases of palatal cancers secondary to reverse smoking were available for the study. Analysis was done based on History, Physical examination, Special investigations and response to treatment. 


\section{Inclusion Criteria}

Age not more than 75 years, ECOG performance status of 0 to 2, Histopathologically/cytologically proven Squamous cell carcinomas of hard or soft palate with sole history of reverse smoking habit with no previous history of radiation or chemotherapy, normal blood counts, renal and liver function test results and no major comorbidities.

\section{Exclusion Criteria}

Age more than 75, ECOG P.S 3 or more, metastatic disease, severe comorbidities like Cardiac or Pulmonary diseases, Cirrhosis or Renal failure, other addictions like gutkha, alcohol etc. Abnormal blood parameters like Neutropenia or thrombocytopenia, abnormal RFT or LFT. Cases treated in the Department of Radiation Oncology between 2012 and 2015 were analysed. All cases were treated by chemo-irradiation, since surgical oncology wing was not available in the institute. More locally advanced lesions were treated by Neoadjuvant chemotherapy followed by weekly Cisplatin combined with Radical radiation, whereas for more early lesions weekly Cisplatin with concurrent Radiation was administered.

History wise cases we stratified based on age, gender, chronicity of habit and economic status. Cases were analysed based on Histopathology, staging based on physical examination and special investigations. Finally analysis was done for response to treatment classifying as complete response, partial response and no response/progressive disease based on RECIST criteria, mostly on clinical grounds and some by imaging at the end of the treatment.

Patients were treated by Telecobalt machine with parallel opposed portals. For very early lesions, only the primary tumour was taken as target volume and radiation was delivered by employing mouth bite to depress the mandible away from the field. Since most cases were locally advanced, they were treated using portals encompassing primary tumour and neck nodes with common fields.

Neoadjuvant chemotherapy was done by administering three weekly Cisplatin $80 \mathrm{mg} / \mathrm{Sq} . \mathrm{M}$ on day 1 and day 2, while 5 -Fluorouracil was given as $750 \mathrm{mg} / \mathrm{Sq} . \mathrm{M}$ on days 1 to 3 . After two to three cycles, Radical Radiation up to a dose of 6,600 CGy in 33 fractions in conventional fractions. (4,400 CGy was for the initial half, which was coned down and further 2,200 CGy in eleven fractions were given). For those treated with concurrent Chemoradiation, Cisplatin was administered as 40 $\mathrm{mg} / \mathrm{Sq} . M$ every week along with radical radiation of 6,600 CGy in 33 fractions in conventional fractions. Post treatment patients were asked to come for follow-up every three months.

\section{RESULTS}

Amongst the 62 patients who were available for the study, 14 patients discontinued the treatment mid-way, probably due intolerance to the toxicity of the treatment and were not available for follow-up. The rest of 48 patients were available for analysis.All the patients were above thirty years underlining the fact that there needs a lag period of many years before malignant changes occur.

\begin{tabular}{|c|c|c|c|}
\hline No. & Age in Years & Number & Percent \\
\hline 1) & 30 to 40 & 04 & $6 \%$ \\
\hline 2$)$ & 40 to 50 & 20 & $32 \%$ \\
\hline 3$)$ & 50 to 60 & 28 & $45 \%$ \\
\hline 4$)$ & $>60$ & 10 & $16 \%$ \\
\hline \multicolumn{3}{|c|}{ Age Stratification } \\
\hline
\end{tabular}

Maximum incidence was found in the age group 50 to 60 years (45\%) and minimum in 30 to 40 years (6\%).

\begin{tabular}{|c|c|c|}
\hline Females & 38 & $61 \%$ \\
\hline Males & 24 & $39 \%$ \\
\hline \multicolumn{3}{|c|}{ Gender Distribution } \\
\hline
\end{tabular}

Gender wise, females outnumbered men. There were 38 females and 24 males in the study. This is in accordance with the fact that the habit is more often seen in females. Ratio wise, it is 1.5:1.0 females is to males. This finding was also corroborated by C.R.R.M. Reddy et al in his study of "Carcinoma hard palate in India in relation to Reverse smoking of Chuttas."

\section{Treatment Responses}

Results were analysed at the first follow-up, i.e. 3 months post treatment.

\begin{tabular}{|c|c|c|c|}
\hline Response & Total & Females & Males \\
\hline Complete & $09(19 \%)$ & $6(67 \%)$ & $3(33 \%)$ \\
\hline Partial & $29(60 \%)$ & $15(51 \%)$ & $14(49 \%)$ \\
\hline Progressive Disease & $10(21 \%)$ & $8(80 \%)$ & $2(20 \%)$ \\
\hline \multicolumn{3}{|c|}{ Totally 48 Cases were Studied } \\
(14 Could Not Complete Therapy) \\
\hline
\end{tabular}

We had observed relatively better response to therapy in these cases compared to those palatal cancers due to other reasons stage wise. Overall response rates were $80 \%$ (Ref NCBI resource Shau H. Huang et al), which had 75\% LRCs.

\begin{tabular}{|c|c|c|c|}
\hline Stage & TNM & Number & Responses \\
\hline Stage I & T1,N0,M0 & NIL & ----- \\
\hline \multirow{2}{*}{ Stage II } & T2,N0,M0 & $2(3 \%)$ & $\begin{array}{c}\text { C.R-1(50\%) } \\
\text { P.R-1(50\%) }\end{array}$ \\
\hline Stage III & T1,2\&3 N1,M0 & $16(26 \%)$ & $\begin{array}{c}\text { C.R-4(25\%) } \\
\text { P.R } 12(75 \%)\end{array}$ \\
\hline \multirow{2}{*}{ Stage IV } & T4,A\&B N1,M0 & $44(71 \%)$ & $\begin{array}{c}\text { C.R-4(9\%) }-29(65 \%) \\
\text { Progressive-10(20\%) }\end{array}$ \\
\cline { 2 - 2 } & & & Stage Wise Distribution and Responses \\
\hline
\end{tabular}

Majority of cases were advanced growths involving nasal cavity and Maxillary antra superiorly, alveoli and mandible laterally, and even hypopharynx inferiorly, constituting Stage IV-A cancers.

Among stage II disease the complete response seen in was 1 out of 2 (50\%), Stage III CR was seen in 4/16 (25\%), partial responses were seen in $12 / 16(75 \%)$ and in Stage IV the complete responses were seen in $4 / 44(9 \%)$ and partial responses in 29/44 (65\%).

\begin{tabular}{|l|c|}
\hline Squamous cell carcinomas & $60(96 \%)$ \\
\hline Adenoid cystic carcinomas & $02(04 \%)$ \\
\hline \multicolumn{2}{|c|}{ Histopathology Wise Distribution } \\
\hline
\end{tabular}

Most of the cases in our study were Squamous cell carcinomas (96\%) and only two cases were Adenoid cystic carcinomas, which means tobacco induced cancers are epithelial rather than salivary in origin. ${ }^{1,11}$

\section{Chronicity}

All cases had smoking history of over 15 years. 


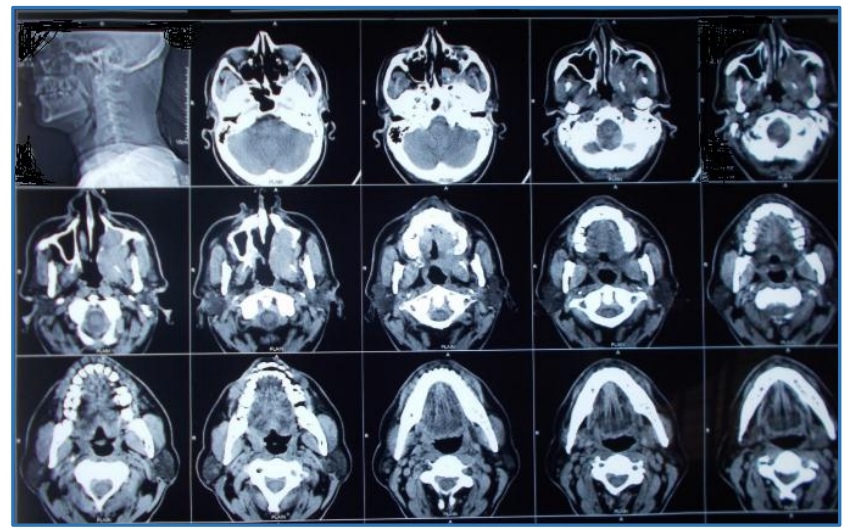

Fig. 1: CT Scan Images of Palatal Growth involving Left Maxillary Antrum

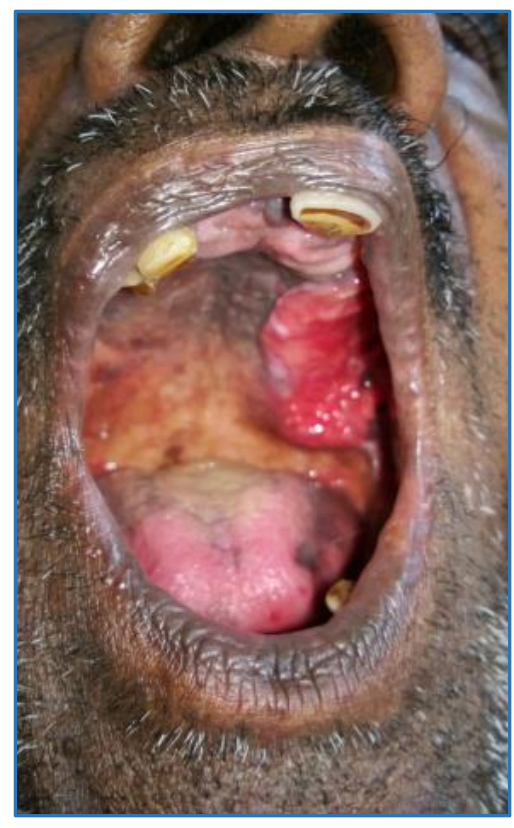

Fig. 2: Illustrative Clinical Photo of Palatal Growth

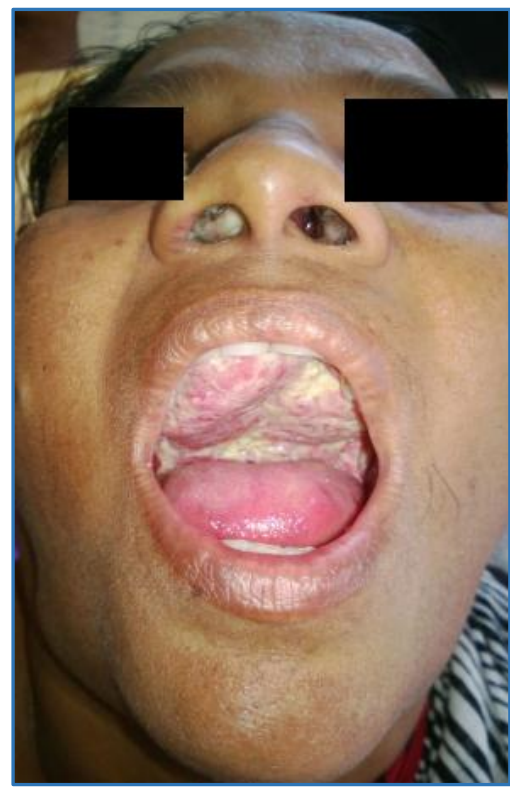

Fig. 3: Illustrative Clinical Photo showing Extensive Palatal Growth

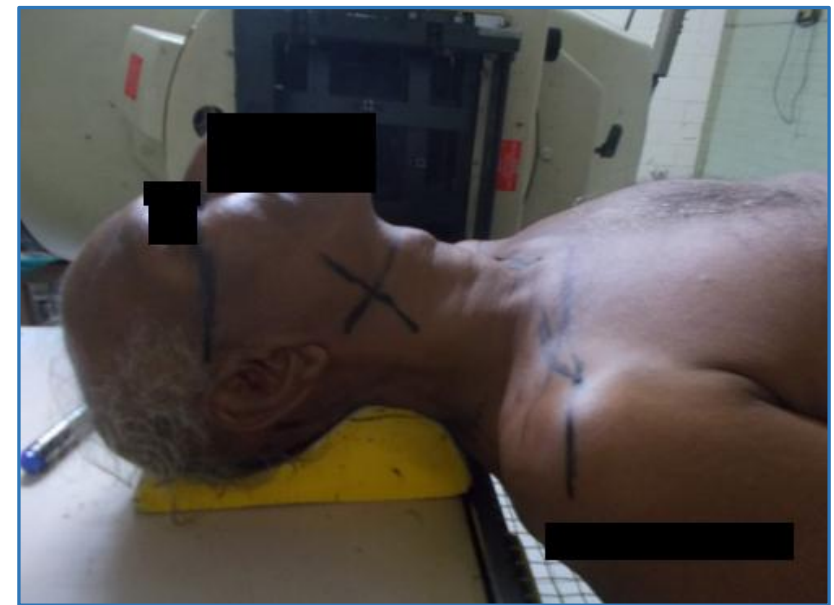

Fig. 4: Patient on Treatment Couch showing Radiation Fields

\section{DISCUSSION}

Head and neck cancers predominate in incidence in most parts of India, but sub-site wise the tongue, buccal mucosa and alveolar cancers constitute the highest numbers unlike in other parts of the world where Head and Neck cancers constitute fifth in frequency. ${ }^{1,2}$ The following is the distribution of oral cancers by "Cancer Research UK" in UK.

\begin{tabular}{|c|c|c|c|c|}
\hline \multicolumn{2}{|c|}{ Oral Cancer (C00-C06, C09-C10, C12-C14): 2010-2012 } \\
\hline & $\begin{array}{c}\text { Average } \\
\text { Cases }\end{array}$ & $\%$ & $\begin{array}{c}\text { Average } \\
\text { Cases }\end{array}$ & $\%$ \\
\hline Lip (C00) & 245 & $5.4 \%$ & 121 & $5.2 \%$ \\
\hline $\begin{array}{c}\text { Base of } \\
\text { Tongue (C01) }\end{array}$ & 573 & $12.5 \%$ & 172 & $7.4 \%$ \\
\hline $\begin{array}{c}\text { Other and } \\
\text { Unspecified } \\
\text { Parts of } \\
\text { Tongue (C02) }\end{array}$ & 826 & $18.0 \%$ & 572 & $24.7 \%$ \\
\hline Gum (C03) & 191 & $4.2 \%$ & 177 & $7.7 \%$ \\
\hline $\begin{array}{c}\text { Floor of } \\
\text { Mouth (C04) }\end{array}$ & 346 & $7.5 \%$ & 174 & $7.5 \%$ \\
\hline Palate (C05) & 269 & $5.9 \%$ & 197 & $8.5 \%$ \\
\hline $\begin{array}{c}\text { Other and } \\
\text { Unspecified } \\
\text { Parts of } \\
\text { Mouth (C06) }\end{array}$ & 350 & $7.6 \%$ & 291 & $12.6 \%$ \\
\hline Tonsil (C09) & 915 & $20.0 \%$ & 325 & $14.0 \%$ \\
\hline $\begin{array}{c}\text { Oropharynx } \\
\text { (C10) }\end{array}$ & 251 & $5.5 \%$ & 80 & $3.5 \%$ \\
\hline $\begin{array}{c}\text { Piriform Sinus } \\
\text { (C12) }\end{array}$ & 278 & $6.1 \%$ & 62 & $2.7 \%$ \\
\hline $\begin{array}{c}\text { Hypopharynx } \\
\text { (C13) }\end{array}$ & 162 & $3.5 \%$ & 76 & $3.3 \%$ \\
\hline $\begin{array}{c}\text { Other and Ill- } \\
\text { Defined Lip, } \\
\text { Oral Cavity } \\
\text { and Pharynx } \\
\text { (C14) }\end{array}$ & 181 & $4.0 \%$ & 68 & $2.9 \%$ \\
\hline Total & $\mathbf{4 , 5 8 6}$ & $\mathbf{1 0 0 . 0 \%}$ & $\mathbf{2 , 3 1 5}$ & $\mathbf{1 0 0 . 0 \%}$ \\
\hline Distribution of Cases Diagnosed by Anatomical Site, UK \\
\hline
\end{tabular}


Palatal cancers are relatively uncommon in most parts of the country, but some parts of the country like East and West Godavari or Srikakulam districts of Andhra Pradesh, it is seen in significant numbers. This is directly attributable to the peculiar habit of Reverse smoking existent in this part of the country. Though this is a significant health hazard in this population, there have been very few studies in the past that have investigated the problem. This habit is seen globally in other countries like Srilanka or South American countries like Argentina, Bolivia, etc.

A study was conducted in the cross-section of population by Van Der Eb, Satyanarayana Gavarasana et al in Srikakulam district for screening, but our study has included those cases that are frankly malignant and were due to reverse smoking. Again J. J. Pindborg, F. S. Mehta et al also did a cross-sectional study amongst the population of Srikakulam district of Andhra Pradesh as a screening measure. Hence, an attempt was made to study those cases of palatal cancers arising out of this cult of reverse smoking amongst the patients coming to Government Hospital, Kakinada.

The reasons for this bizarre habit of smoking are not clear. The folklore attributes the cult or habit of reverse smoking or locally called "Adda poga or Adda chutta" to more than one reasons. The conservative women prefer to hide the burning ends of cigars inside their mouths from men as a mark of obedience. Other reasons put forth are that the women would take their children in their lap to breast feed or console them and to prevent sparks dropping on them, resort to Adda poga. Some people report better effect of smoking if burnt ends are turned inside adding thermal effect in addition to tobacco smoke. Whatever the reasons, this habit has turned into a cult over decades. The smoke which contains nicotine, methanol and other nitrosamines along with heat is postulated to add to carcinogenetic effect. Since the habit is more prevalent in women, the incidence also is higher in women. This observation of higher incidence in females was corroborated in our study. This finding of ours is also corroborated by C.R.R.M. Reddy et al in his study of "Carcinoma hard palate in India in relation to Reverse smoking of Chuttas."

Since a lag period of more than 10 to 15 years is required to induce carcinogenesis, most of the subjects were between 50 to 60 years old. Most cases were in Stage IV, since most were locally advanced and had already spread to other adjacent structures like Nasal cavity, Maxillary antra, Hypopharynx etc., mostly because of ignorance due to lack of literacy and due to non-availability of medical services. Hence, most cases received neo-adjuvant chemotherapy before Definitive Radiation Therapy in order to downstage the disease. It is worthwhile to point out that Cancer Research UK 2013 showed 75\% disease control rates for palatal cancers arising due to other aetiological factors, whereas our study is showing $80 \%$ disease controls.

In majority of cases with Stage IV disease treated with Radical radiation, a distressing complication due to perforation of the palate occurred, leading to problems of deglutition due to nasal regurgitation of feeds necessitating the need for an expert dental counselling and placement of obturator in this group of patients.

\section{CONCLUSION}

Finally, in conclusion it can be said that the noticeably higher incidence of palatal cancers in the East Godavari district is secondary to the habit of reverse smoking existing in some groups here.

It can also be said that palatal cancers due to this habit constitutes a case of preventable cancer at all three levels, primary by altogether giving up the habit, secondary prevention by screening this set of population for pre-clinical lesion and early cancers and offering treatment and tertiary prevention by instituting definitive therapy.

The results of treatment by chemo-irradiation in palatal cancers caused by reverse smoking are marginally better when compared to other causes of palatal cancers. In Stage III and IV, complete response is $20 \%$ and partial response is $80 \%$ at first follow-up.

\section{REFERENCES}

1. Shantha V, KrishnaMurthy S. A study of aetiological factors in oral squamous cell carcinoma. Br J Cancer 1959;13:381-8.

2. Reddy DG, Reddy DB, Rao PR, et al. Experimental production of Cancer with tobacco, tar and heat. Cancer 1960;13(2):263-9.

3. Khanolkar VR. Habits and customs as causative agents for cancer. Anniversary address 1967:33B(5 \& 6)307-314.

4. Pindborg JJ, Mehta FS, Gupta PC, et al. Reverse smoking in Andhra Pradesh: a study of palatal lesions among 10,169 villagers. British Journal of Cancer 1971;25(1):10-20.

5. Reddy CRRM, Ramulu C. Review of carcinoma of hard palate in Vishakapatnam area. International College of Surgeons 1972:4.

6. Reddy CR. et al. Carcinoma hard palate in India in relation to reverse smoking habit of chuttas. J of Cancer Institute 1974;53(3):615-9.

7. van der Fb MM, Leyten EM, Gavarasana S, et al. Reverse smoking as a risk factor for palatal cancer: a cross sectional study in rural Andhra Pradesh, India. Int J Cancer 1993;54(5):754-8.

8. Maiyer. Case-control studies on relative risk of head \& neck cancers in association with tobacco and alcohol. Acta OtoLaryngyol Supplementum 1997:526-32.

9. Yorozu A, Sykes AJ, Slevin NJ. Carcinoma of the hard palate treated with radiotherapy: a retrospective review of 31 cases. Oral Oncol 2001;37(6):493-7.

10. Huang SH, O'Sullivan B. Oral cancer: current role of radiotherapy and chemotherapy. Med Oral Patol Oral Cir Bucal 2013;18(2):e233-e40.

11. Jadhav KB, Gupta N. Clinicopathological prognostic implicators of oral squamous cell carcinoma: need to understand and revise. N Am J Med Sci 2013;5(12):671-9. 